\title{
New records of the subfamily Oscinellinae (Diptera; Chloropidae) from Iran
}

\author{
R. Namaki Khamneh, ${ }^{1}$ S. Khaghaninia, ${ }^{1}$ E. Gilasian² \\ ${ }^{1}$ Department of Plant Protection, University of Tabriz, Tabriz; ${ }^{2}$ Insect Taxonomy Research \\ Department, Iranian Research Institute of Plant Protection, Tehran, Iran
}

\begin{abstract}
A faunistic study of the subfamily Oscinellinae was investigated in Shabestar region (East Azarbaijan province, Iran) during 2013-2014. Four species Aphanotrigonum bicolor Nartshuk, 1964, Dicraeus sabroskyi Beschovski, 1977, Lasiambia albidipennis (Strobl, 1893) and Lasiambia coxalis (von Roser, 1840) are newly recorded from Iran. In addition, one genus Lasiambia Sabrosky, 1941 is recorded for the first time from Iran. The diagnostic characters and photos of the recorded species are provided.
\end{abstract}

\section{Introduction}

The family Chloropidae (Diptera; commonly called Frit flies or Grass flies) with 204 genera and more than 2500 described species is a moderately large family of Acalyptratae (Nartshuk, 2012a). The larvae of this family have a very diverse biology. Most chloropid larvae develop in grass, many species such as Dicraeus raptus (Haliday, 1838), Meromyza saltatrix (Linnaeus, 1761) and Oscinella frit (Linnaeus, 1758) are pests of cereal crops by feeding from seed, bud and shoots, some species of the genus Lipara cause galls on stems, few such as Lasiosina cinctipes (Meigen, 1830) are saprophagous, small numbers such as Thaumatomyia notata (Meigen, 1830) are predators of some

Correspondence: Samad Khaghaninia, University of Tabriz, Department of Plant Protection, Faculty of Agriculture, 51664, Tabriz, Iran.

E-mail: skhaghaninia@gmail.com

Key words: Chloropidae; Oscinellinae; Shabestar; Iran; new records.

Acknowledgements: the authors sincerely thank Dr. Stepan Kubik, Department of Zoology and Fisheries, Faculty of Agrobiology, Food and Natural Resources, Czech University of Life Sciences, who kindly assistance in identifying the materials.

Received for publication: 5 March 2015.

Revision received: 30 April 2015.

Accepted for publication: 12 June 2015.

(C) Copyright R. Namaki Khamneh et al., 2015

Licensee PAGEPress, Italy

Journal of Entomological and Acarological Research 2015; 47:5135

doi:10.4081/jear.2015.5135

This article is distributed under the terms of the Creative Commons Attribution Noncommercial License (by-nc 3.0) which permits any noncommercial use, distribution, and reproduction in any medium, provided the original author(s) and source are credited. insects and some of them such as Liohippelates collusor (Townsend, 1895) (commonly called eye gnats) are very annoying pests for humans by attracting and transmitting diseases to the eye (Sabrosky, 1941; Chvala et al., 1974; Deeming and Al-Dhafer, 2012).

Species of the subfamily Oscinellinae differ from the other closest subfamilies of Chloropidae by the following combination of characters: ocellar setae long, straight or recurved and convergent, without incurved humeral setae: vein $\mathrm{C}$ along margin of wings reaching to vein $\mathrm{M}_{1+2}$; hypopygium usually with well-developed cerci and surstylus (Nartshuk et al., 1988; Nartshuk and Andersson, 2013).

Some new taxonomic studies and catalogue on the world fauna of chloropids are as follows: Wheeler $(2003,2007)$ described a new species and genera of this family from freshwater wetlands in eastern Canada and Costa Rica, respectively. Wheeler and Forrest (2003) described seven new species from Galapagos Islands. Kubik (2006) described two new species from Zambia. Nartshuk (2012a, 2012b) provided a checklist of the world genera of the family Chloropidae and also described three new species from southern Sardinia, respectively. Nartshuk and Andersson (2013) provided a book about species of this family. Nartshuk and Fedoseeva (2011a, 2011b) provided a key to the species of the genus Meromyza Meigen, 1830.

Like many other families of Diptera, the Chloropidae of Iran are poorly known. Only seventeen species belonging to eleven genera of the subfamily Oscinellinae have been previously recorded from Iran (Nartshuk, 1984; Modarres-Awal, 2011; Khaghaninia et al., 2014a, 2014b). This study adds four species of this subfamily for the Iranian insect fauna.

\section{Materials and methods}

Adult specimens were collected by standard sweep netting in grassland habitats from Shabestar region located in northern west of Iran during 2013-2014. The samples were killed in a killing jar containing potassium cyanide. The species were identified based on Beshovski (1976); Nartshuk et al. (1988); Nartshuk (2011); Nartshuk \& Andersson (2013). Hypopygium and ovipositors were cleared in $10 \%$ $\mathrm{KOH}$. Images were obtained using a microscope (Nikon SMS 1000) equipped with a camera (Olympus $10 \mu$ ).

The material examined is deposited in collections of the following institutions: ICHMM: Insect Collection of Professor Hasan Maleki Milani, University of Tabriz, Tabriz, Iran and CULS: Czech University of Life Sciences collections.

\section{Results}

Four species and one genus marked with an asterisk are newly reported for the Iranian oscinellid fauna [Aphanotrigonum bicolor 
Nartshuk, 1964, Dicraeus sabroskyi Beschovski, 1977, Lasiambia albidipennis (Strobl, 1893) and Lasiambia coxalis (von Roser, 1840)]. Locality, Diagnostic characters, biology and distribution of identified species at the present study are given briefly. Diagnostic characters adapted by Beshovski (1976); Nartshuk et al. (1988); Nartshuk (2011) and Nartshuk \& Andersson (2013).

\section{The species found}

\section{Genus Aphanotrigonum Duda, 1932}

Aphanotrigonum bicolor Nartshuk, 1964 (Figure 1A-C)

MATERIAL EXAMINED: (1§): Shabestar (Shanejan), 38¹4'12.3” N, 4543’11.5” E, 1649 m, 4 Jun. 2014; leg. R. Namaki Khamneh.

DIAGNOSTIC CHARACTERS: Body length $2 \mathrm{~mm}$; head mainly yellow; apex of scutellum, part of pleura and shoulders yellow; vertical triangle as long as wide and black; stripes of mesonotum black (Figure 1A); antennal grooves separated by narrow keel; occiput and postgena black; antenna yellow; postpedicel rounded; arista yellow; legs brownish-yellow; abdomen brownish-yellow (Figure 1B); male genitalia: epandrium small, cerci not tapering, surstyli not narrow (Figure 1C).

BIOLOGY: Larvae are saprophagous, feeding from decomposing stem and spikelets of Poaceae (Nartshuk et al., 1988).

DISTRIBUTION: Turano-European (Nartshuk, 2011).

\section{Genus: Dicraeus Loew, 1873}

Dicraeus sabroskyi Beschovski, 1977 (Figure 1A and B)

MATERIAL EXAMINED: ( $4 \hat{\jmath} \hat{\jmath}, 15$ 우): Shabestar (Haftcheshmeh),

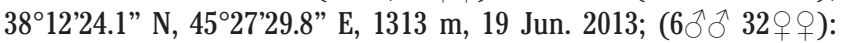
(Til), 38¹5’31.7" N, 45²8'50.8” E, 1489 m, 26 Jun. 2014; leg. R. Namaki Khamneh.

DIAGNOSTIC CHARACTERS: Body length 2-2.5 mm; background colour gray to black; gena yellow; vertical triangle black, shiny; antenna black, postpedicel rounded; arista black; thorax black; legs black; palpi yellow (Figure 2A); male genitalia: hypopygium large; cerci slendered; surstyli long, broad and with distinct setae (Figure 2B).
BIOLOGY: Larvae are phytophagous.

DISTRIBUTION: Bulgaria (Beshovski, 1976).

\section{Genus: Lasiambia Sabrosky, 1941}

Lasiambia albidipennis (Strobl, 1893) (Figure 3A-C)

MATERIAL EXAMINED: (1 $\left.{ }^{\circ}\right)$ : Shabestar (Shanejan), 38¹4'12.3” N, 4543'11.5” E, 1649 m, 5 Jul. 2014; leg. R. Namaki Khamneh.

DIAGNOSTIC CHARACTERS: Body length $2.5-3 \mathrm{~mm}$, colour black; head mainly black; vertical triangle shiny black; thorax shiny black (Figure 3A); vibrissal corner protruding beyond margin of eye; gena brownish; legs black (Figure 3B); antenna brownish; postpedicel relatively rounded; arista mainly yellow, black in basal third; palpi brown (Figure 3C). 1934).

DISTRIBUTION: South-European (Nartshuk, 2011).

Lasiambia coxalis (von Roser, 1840) (Figure 4A-C)

MATERIAL EXAMINED: (1ㅇ): Shabestar (Shanejan), 38¹3’39.3” N, 4543’07.6” E, 1602 m, 5 Jul. 2014; leg. R. Namaki Khamneh.

DIAGNOSTIC CHARACTERS: Body length $2.5 \mathrm{~mm}$; shiny black species; vertical triangle shiny black; thorax shiny black (Figure 4C); vibrissal corner protruding beyond margin of eye; gena yellow; occiput and postgena black; legs black and yellow; wing dark (Figure 4B); antenna bicolour yellow and black; postpedicel rounded; arista black (Figure 4A).

BIOLOGY: Larvae are parasitic and develop in egg masses of Chrysochaon dispar Germar (Orthoptera: Acrididae) in other Acrididae (Nartshuk \& Andersson, 2013).

DISTRIBUTION: Europe (Nartshuk \& Andersson, 2013).

\section{Discussion and conclusions}

Dicraeus sabroskyi is the most frequent species among the ones identified in the present study. Furthermore, Lasiambia albidipennis and Lasiambia coxalis were collected from grasslands of Shabestar
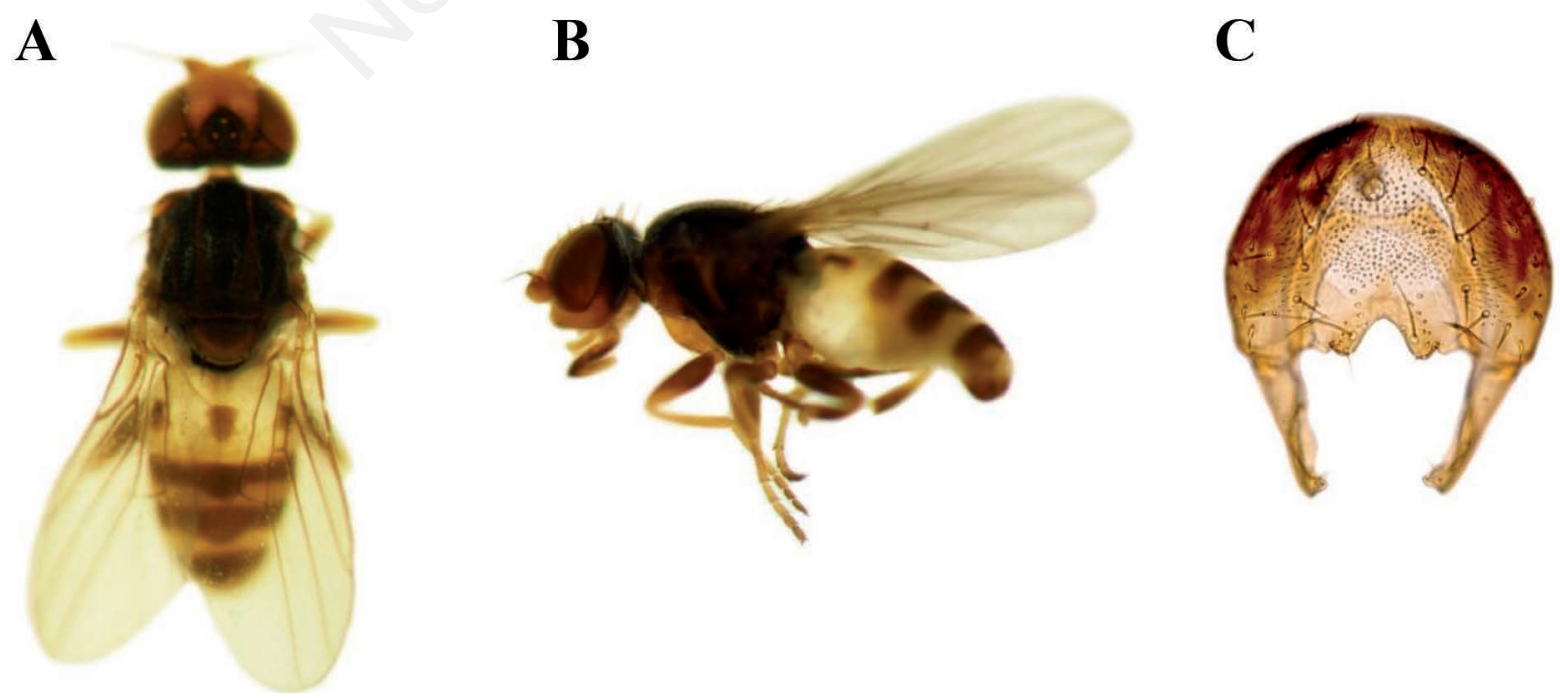

Figure 1. Aphanotrigonum bicolor Nartshuk, 1964 (male); A) Dorsal view; B) Lateral view; C) Dorsal view of hypopygium. 

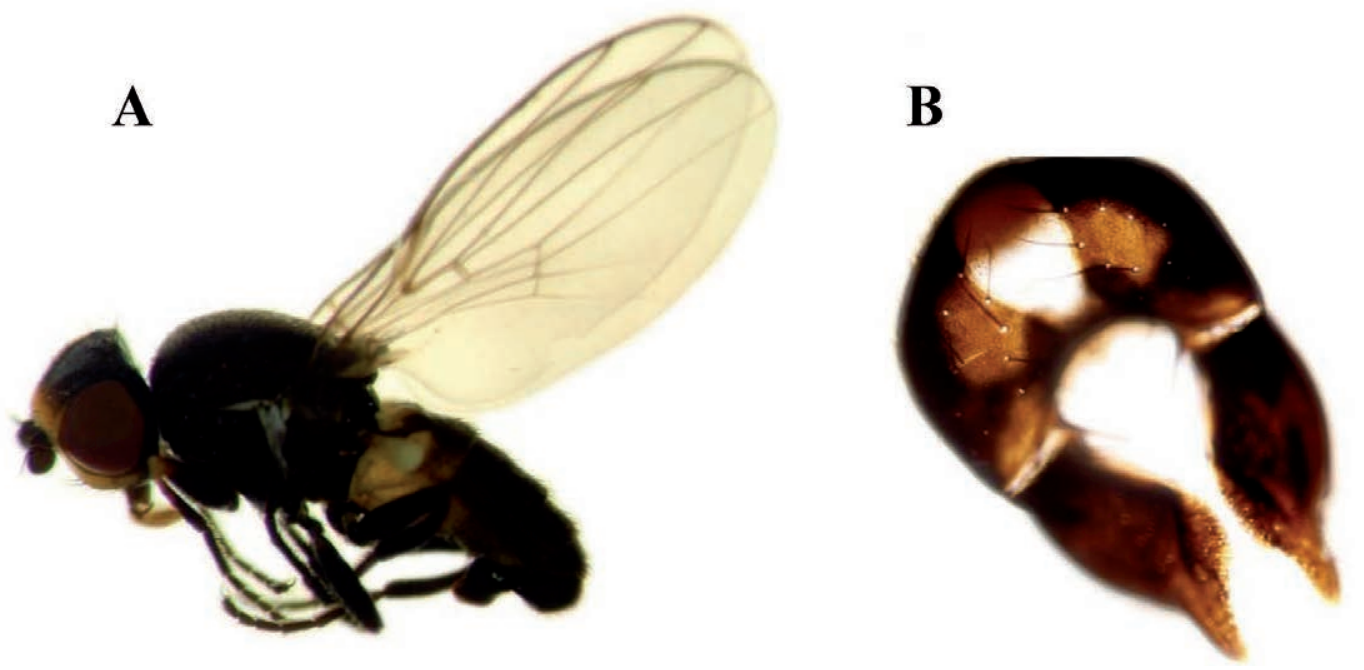

Figure 2. Dicraeus sabroskyi Beschovski, 1977 (male); A) Lateral view; B) Dorsal view of hypopygium.
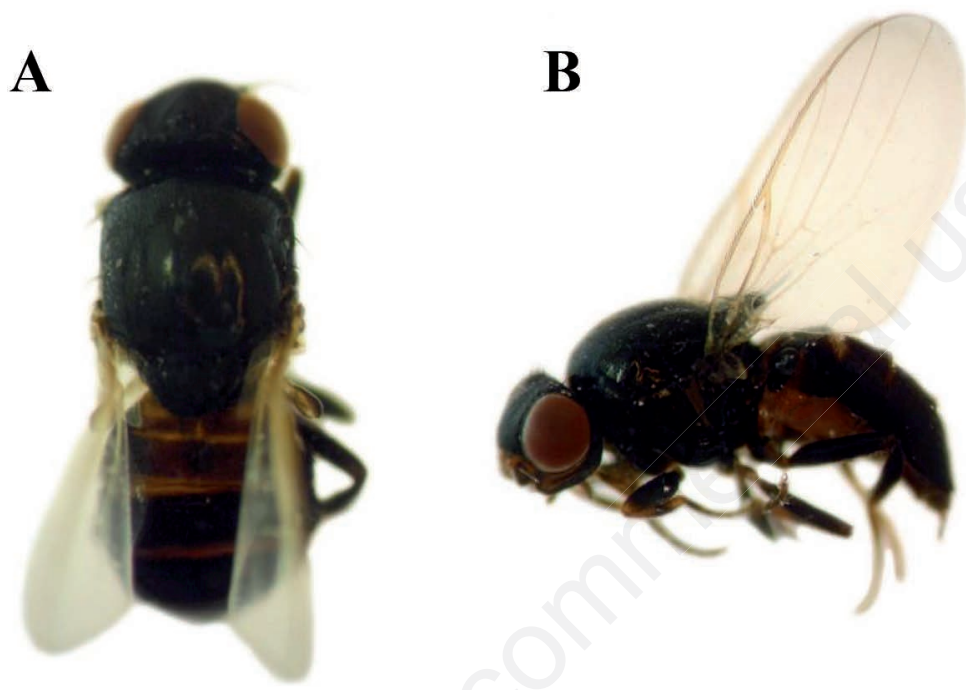

C

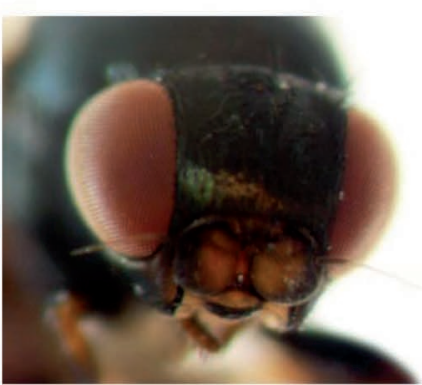

Figure 3. Lasiambia albidipennis (Strobl, 1893) (female); A) Dorsal view; B) Lateral view; C) Frontal view of head.
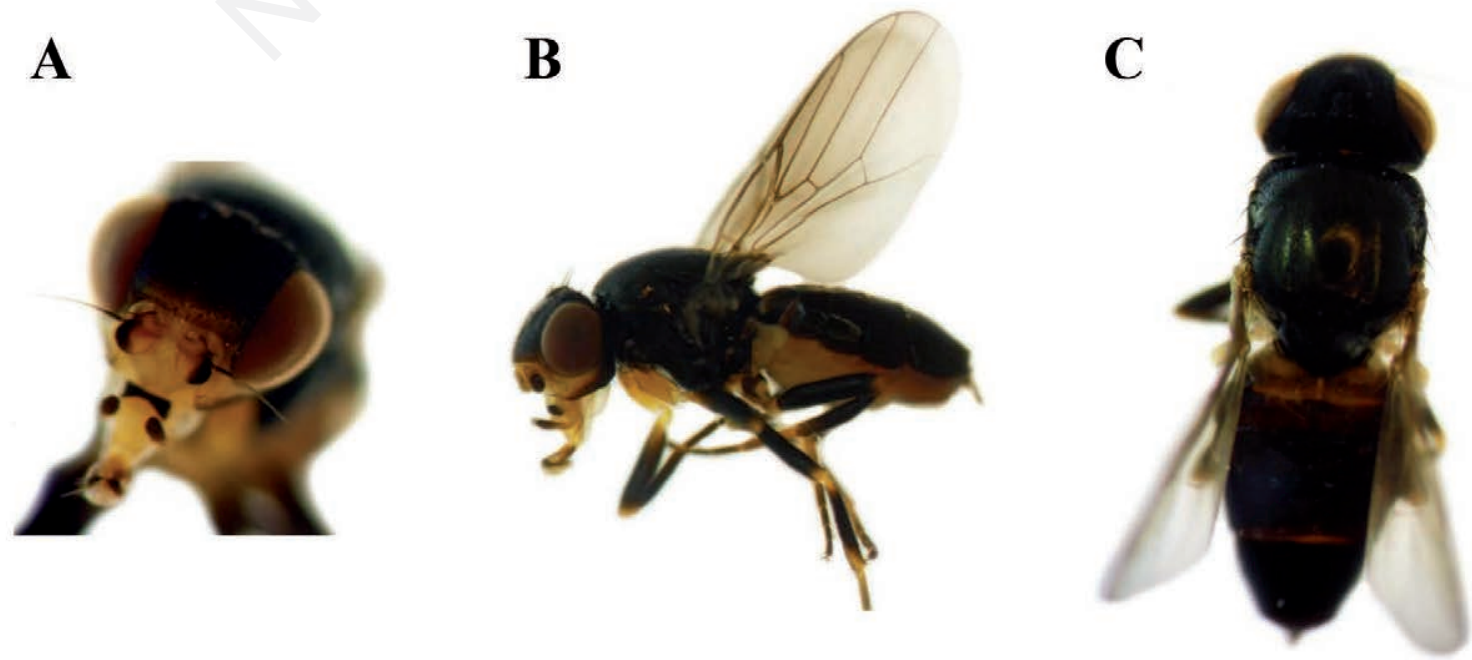

Figure 4. Lasiambia coxalis (von Roser, 1840) (female); A) Frontal view of head; B) Lateral view; C) Dorsal view. 
region. Nartshuk \& Andersson (2013), reported L. coxalis from egg masses of Acrididae and Séguy (1934) observed L. albidipennis in the stems of Brassica oleraceae, it explains why we collected just one female of each species in an area with few acridids populations as well as few wild brassicaeus plants.

Before this study, Dicraeus sabroskyi was collected and described only from Bulgaria (Beshovski, 1976), suggesting that this species is very rare in Palearctic region. However, a relatively high population has been collected in the Shabestar region, emphasizing ecological similarity of this region with the ones where the species was found.

Before this study 18 species belonging to the subfamily Oscinellinae were recorded from Iran, present work adds other four species to the Iranian checklist. The known Iranian frit flies of Oscinellinae are about one fourth of the subfamily Chloropinae (Nartshuk, 1984; ModarresAwal, 2011; Khaghaninia et al., 2014a, 2014b). This contradicts common knowledge that Oscinellinae exceed Chloropinae around the world, suggesting that Iranian checklist is still incomplete and needs further study.

\section{References}

BESHOVSKI V., 1976 - Dicraeus sabroskyi sp. n. Diptera, Chloropidae a new species from Bulgaria. - Acta. Zool. Bulg. 6: 54-57.

CHVALA M., DOSKOCIL J., MOOK J.H., POKORNY V., 1974 - The Genus Lipara Meigen (Diptera, Chloropidae), systematics, morphology, behaviour, and ecology. - Tijdschr. Ent. 117: 1-25.

DEEMING J.C., AL-DHAFER H.M., 2012 - Chloropidae from the Arabian Peninsula (Diptera: Cyclorrhapha). - Zool. Middle East. 58: 4-88.

KHAGHANINIA S., GHARAJEDAGHI Y., NAMAKI KHAMNEH R. 2014a Some of the chloropid flies (Diptera: Chloropidae) of wheat fields from East Azerbaijan province with new pest records for Iran. Appl. Res. Plant Prot. 3: 65-75.

KHAGHANINIA S., KUDIK S., GARAJEDAGHI Y., 2014b - New data on grass flies (Diptera, Chloropidae) from Iran. - Dipterist Dijest 21: 135-142.

KUBIK S., 2006 - Two new species of Pselaphia (Diptera, Chloropidae) from Zambia - Biologia, Bratislava 61: 159-160.

MODARRES-AWAL M., 2011 - List of agricultural pests and theirnatural enemies in Iran - Ferdowsi University of Mashhad publication, Mashhad, third edition, $447 \mathrm{pp}$.
NARTSHUK E.P., 1984 - Family Chloropidae. In: SOÓS Á. \& PAPP L. (Eds.), Catalogue of Palaearctic Diptera. - Hungarian Natural History Museum, Budapest, 10: 222-298.

NARTSHUK E.P., 2011 - Chloropidae from southern Sardinia (Diptera: Cyclorrhapha, Acalyptratae). - Conserv. Habitat. Vertebrati 5: 717732.

NARTSHUK E.P., 2012a - A check list of the world genera of the family Chloropidae (Diptera, Cyclorrhapha, Muscomorpha). - Zootaxa 3267: 1-43.

NARTSHUK E.P., 2012b - Three new species of Chloropidae (Diptera) from southern Sardinia. - Zootaxa 2318: 545-551.

NARTSHUK E.P., ANDERSSON H., 2013 - The Frit flies (Chloropidae, Diptera) of Fennoscandia and Denmark. - Brill Academic Publishers, Leiden, $277 \mathrm{p}$.

NARTSHUK E.P., FEDOSEEVA L.I., 2011a - A review of the grass flies of the genus Meromyza Meigen, 1830 (Diptera, Chloropidae) of the Palaearctic fauna, with a key to the species, analysis of synonymy, host specialization, and geographical distribution: part 1. Entomol. Rev. 91: 103-120.

NARTSHUK E.P., FEDOSEEVA L.I., 2011b - A review of the grass flies of the genus Meromyza Meigen, 1830 (Diptera, Chloropidae) of the Palaearctic fauna, with a key to the species, analysis of synonymy, host specialization, and geographical distribution: part 2. Entomol. Rev. 91: 778-795.

NARTSHUK E.P., SMIRNOV E.S., FEDOSCEVA L.I., 1988 - Family Chloropidae. In: BEI-BIENKO G.Y. (Ed.), Keys to the insects of the European part of the USSR, Volume 5, part 1: Diptera (Insecta): NHBS. - GY Bei-Bienko, Pensoft: 669-731.

SABROSKY C.W., 1941 - The Hippelates flies or eye gnats: preliminary notes. - Canad. Entomol. 73: 23-7.

SÉGUY E., 1934 - Faune de France, 28. Diptères (Brachycères) (Muscidae Acalypterae et Scatophagidae). - Lechavalier, Paris, I-Iv $+832 \mathrm{pp}$.

WHEELER T., 2003 - A new brachypterous species of Elachiptera Becker (Diptera: Chloropidae) from freshwater wetlands in eastern Canada. - Zootaxa 360: 1-6.

WHEELER T., 2007 - Two new genera of oscinellinae Chloropidae (Diptera) from Costa Rica. - Zootaxa 1413: 47-53.

WHEELER T., FORREST J., 2003 - The Chloropidae (Diptera) of the Galápagos Islands, Ecuador. - Insect Sys. Evol. 34: 265-280. 